\title{
QUEEN'S
UNIVERSITY
BELFAST
}

\section{What performance metrics should Journal Editors report? Or, is Impact Factor the only metric in town}

Gray, R., Bressington, D., Jones, M., \& Thompson, D. R. (2021). What performance metrics should Journal Editors report? Or, is Impact Factor the only metric in town. Journal of Advanced Nursing, 77(1), 1-3.

Published in:

Journal of Advanced Nursing

Document Version:

Peer reviewed version

Queen's University Belfast - Research Portal:

Link to publication record in Queen's University Belfast Research Portal

Publisher rights

(c) 2020 John Wiley \& Sons Ltd.

This work is made available online in accordance with the publisher's policies. Please refer to any applicable terms of use of the publisher.

\section{General rights}

Copyright for the publications made accessible via the Queen's University Belfast Research Portal is retained by the author(s) and / or other copyright owners and it is a condition of accessing these publications that users recognise and abide by the legal requirements associated with these rights.

Take down policy

The Research Portal is Queen's institutional repository that provides access to Queen's research output. Every effort has been made to ensure that content in the Research Portal does not infringe any person's rights, or applicable UK laws. If you discover content in the Research Portal that you believe breaches copyright or violates any law, please contact openaccess@qub.ac.uk. 


\section{What performance metrics should Journal editors report? Or, is Impact Factor the only metric in town}

Richard Gray ${ }^{1,2 *}$, Dan Bressington ${ }^{3,4}$, Martin Jones ${ }^{2}$, David Thompson ${ }^{5}$

1. School of Nursing and Midwifery, La Trobe University, Melbourne, Australia

2. Academic Department of Rural Health, University of South Australia, Adelaide,

Australia

3. School of Nursing, Hong Kong Polytechnic University, Hong Kong

4. School of Nursing and Midwifery, Charles Darwin University, Darwin, Australia

5. School of Nursing and Midwifery, Queens University Belfast, Belfast, United Kingdom

Correspondence: Professor Richard Gray, School of Nursing and Midwifery, La Trobe University, Melbourne, VIC 3086, Australia

R.Gray@latrobe.edu.au 
Every June journal editors start to get excited, not in anticipation of their summer holiday (if you live in the Northern hemisphere). No, they are excited because in quick succession the Clarivate Analytics Journal Citation Report (JCR) Impact Factor, SCOPUS Cite Score, and Google Scholar h5 index are all released. Who is up, who is down? Twitter accounts poised, within minutes of their release editors take to the web humblebragging their latest factors, scores and indexes. These numbers matter; who hasn't said to a PhD student when asked where they should publish, "aim high." Which translates to, "the journal with the highest impact factor". Indeed, in Australia the impact factor really matters as a key performance indicator, with the three-yearly Excellence in Research for Australia (ERA) exercise determining the quality of research based on where it is published (Council, 2018). The last ERA (2018) developed a journal list (of over 25,000 journals) for the sole purpose of supporting the research evaluation, with journals meeting the following criteria: academic/scholarly; publish original peer reviewed research; have one or more ISSNs; and have been published during the ERA 2018 reference period for research outputs (https:/www.arc.gov.au/excellence-research-australia/era-2018-journal-list). This list encourages (perhaps forces is more accurate) researchers (no doubt pressured by their institution) into publishing in these journals, and the higher the reputation/profile of the journal (i.e. its impact factor), the more likely is a positive outcome for the researcher, their institution and the journal. Though some of these national research exercises are recently downplaying their reliance on journal impact factors and citation counts - for instance, after criticisms of reliance on them and the reliability of journal rankings - most researchers remain sceptical and, to remain in employment, err on the side of caution and still aim to publish in those journals with the highest impact factors. Credit to the - depressingly tortuous and expensive - UK REF system where at least the papers are actually read and rated by someone who is supposed to be an expert.

Over the last 20 years journal reputation and citation metrics have become ever more intimately intertwined. Is this a healthy love affair or does a borderline obsessive editorial devotion to the citation do damage to the scientific method? 
There are essentially four main citation-based metrics - JCR Impact Factor, CiteScore, SJR (SCImago Journal and Country Rank) and the h5-index. Each is produced by a different company using citation data from different sources. Impact factor uses citation data from Web of Science, CiteScore and SJR use SCOPUS data and the h5-index Google Scholar. SCOPUS indexes more journals than the Web of Science; 22,794 (active) and 12,000 (approximately) journals respectively. Google Scholar indexes essentially every publication on the interweb including grey literature and predatory publications (whatever they are). Both Scopus and Google Scholar have limited access to papers published prior to 1990.

Although many researchers know what impact factor measures, sort of, that bigger is better, they are - probably - in the dark about how the measure is actually worked out. Briefly, then this is how the big four are calculated; take a deep breath. Impact Factor is a measure of how often the average paper is cited in a particular year in a particular journal (Glänzel \& Moed, 2002); the 2019 JCR impact factor was calculates the average number of citations in 2019 for papers published in 2017 and 2018. For example, the impact factor for the Journal of Advanced Nursing (JAN) in 2019 is 2.561; this means that on average papers published in the 2017 and 2018 were citated 2.561 times in 2019. This year Scopus - quite radically - changed the methodology used to calculate the CiteScore metric. The 2019 methodology was as follows: the total number of Scopus indexed citations (articles, reviews, conference papers, book chapters, and data papers) from 2016 to 2019 divided by the number of publications published by a journal over the same four-year period. The JAN has a 2019 CiteScore of 3.9. The $h 5$-index is similar in construction to a researcher personal $h$-index. The ' $h$ ' stands for (Jorge E.) Hirsch who first proposed the index in 2005 (Hirsch, 2005). The latest h5-index is the h-index for papers published in 2015 through 2019 (5 years) and is defined as "the largest number $h$ such that $h$ articles published have at least $h$ citations each" (Masic \& Begic, 2016). The higher the h5-index the more prestigious the journal. For example, the JAN has an h5index of 57 meaning that the journal has published 57 papers that have been cited at least 57 times over the last 5 years. JCR impact factor, Scopus CiteScore and H5-index treat each citation equally and are fairly straight forward to calculate (with sufficient motivation). The SCImago SJR applies a slightly different approach, that considers some citations to be more influential than others, this does make intuitive sense; authors are probably more likely to brag about a citation in JAMA than they are the JAN. The SJR therefore accounts for both the 
number of citations and the prestige of the journals where the citations come from. The SJR is therefore a value indicating the mean number of weighted citations received during a selected year per paper published in that journal during the previous three years. The higher the SJR values the more prestigious the journal: JAN's SJR is 1.027.

Four measures - Impact Factor, CiteScore, h5-index, SJR - each attempt to measure the prestige of journals but are calculated using different methodologies using data from different sources. With lockdown time on our hands we thought it might be mildly entertaining to look at the relationships between different prestige measures and find out if there are marked differences between them or do they in fact all pretty much do the same job. One lockdown Sunday afternoon we extracted the Impact Factor, CiteScore, SJR, h5-index and total (Web of Science) citations for the 122 JCR listed nursing journals. Our data are available via this link: https://doi.org/10.26181/5f3dd501ecfe3 if interested.

Across all four indexes the International Journal of Nursing Studies was rated the leading nursing journal. Second and third spots differed between measures. Nursing Outlook and Birth were second and third ranked on Impact Factor, on CiteScore, second and third, were the Journal of Tissue Viability and Nurse Education Today. Nurse Education Today and Journal of Advanced Nursing and Clinical Simulation in Nursing and Nurse Education Today were second and third on the h5-index and SJR respectively. There were some quirky differences in rankings between the different measures. For example, Clinical Simulation in Nursing was ranked second in SJR and $39^{\text {th }}$ in impact factor. Rather than focusing on these idiosyncrasies, we thought it would be more informative to explore if relationships exist between these indexes. We produced a correlation matrix (that can be access via this Figshare link https://doi.org/10.26181/5f3dbcaf3c4b5), all four measures were strongly correlated with Pearson correlation coefficients of between 0.75 (h5-index and Impact Factor) and 0.89 (SJR and CiteScore). This probably suggests these measures are essentially measuring the same construct, presumably journal prestige.

If these prestige metrics are essentially the same it begs the question, is this the only quality metric that matters? Would it be more informative and promote greater transparency if journal editors reported a broader set of metrics that would give a more rounded view of the 
quality of individual journals. This is particularly important when we are witnessing an increase research misconduct, reporting of false findings, and research paper retractions. Adam Marcus and Ivan Oransky, writing in The Scientist in 2012 advocate for a transparency index that could generate a journal quality score. Candidate items (that we have taken the liberty of embellishing) include: average number of reviewers per paper, time from submission to first decision, manuscript rejection rate, number of appeals, number of successful appeals, proportion of papers where data relating to studies available, rates of prospective trial, systematic review observational study registration. Marcus and Oransky (2012) argue that grading journals on how well they share information will promote greater transparency and openness in academic publishing. Ferric Fang and Arturo Casadevall have also introduced the idea of the Retraction Index, a measure of how many papers journals retract for every 1,000 they publish (Fang \& Casadevall, 2011). Having previously reported on the concerningly low rate of retractions in nursing we think this is an excellent idea (AlGhareeb et al., 2018). We are aware that there are some journals that report at least some of these data, but it is hard to argue why all journals can't publish this information in the spirt of open science and transparency. We would be interested in readers opinions on what quality metrics journals should report.

In our opinion Journal editors pay far too much attention to citation-based metrics that whilst interesting - seem to measure the same thing. It seems to us the citation obsession distracts editors from their prime directive, to share scientific knowledge. Transparency means that everyone - researchers, clinicians, educators, managers and patients - can see and understand the publishing process; there can be no favouritism or shenanigans. It might be informative to grade nursing journals against the quality criteria we have set out. Now there's an idea to keep us out of trouble for a few more lockdown Sunday afternoons. 


\section{References}

Al-Ghareeb, A., Hillel, S., McKenna, L., Cleary, M., Visentin, D., Jones, M., Bressington, D., \& Gray, R. (2018). Retraction of publications in nursing and midwifery research: A systematic review. International Journal of Nursing Studies, 81, 8-13. https://doi.org/10.1016/j.ijnurstu.2018.01.013

Bring On the Transparency Index. (n.d.). The Scientist Magazine ${ }^{\circledR}$. Retrieved 3 August 2020, from https://www.the-scientist.com/critic-at-large/bring-on-the-transparency-index40672

Council, A. R. (2018, May 24). Excellence in Research for Australia [Text]. Australian Research Council. https://www.arc.gov.au/excellence-research-australia

Fang, F. C., \& Casadevall, A. (2011). Retracted Science and the Retraction Index. Infection and Immunity, IAI.05661-11. https://doi.org/10.1128/IAI.05661-11

Glänzel, W., \& Moed, H. F. (2002). Journal impact measures in bibliometric research. Scientometrics, 53(2), 171-193. https://doi.org/10.1023/A:1014848323806

Hirsch, J. E. (2005). An index to quantify an individual's scientific research output. Proceedings of the National Academy of Sciences, 102(46), 16569-16572. https://doi.org/10.1073/pnas.0507655102

Masic, I., \& Begic, E. (2016). Scientometric Dilemma: Is H-index Adequate for Scientific Validity of Academic's Work? Acta Informatica Medica, 24(4), 228-232. https://doi.org/10.5455/aim.2016.24.228-232 